University of Windsor Scholarship at UWindsor

Great Lakes Institute for Environmental Research

Publications

Great Lakes Institute for Environmental Research

$11-2015$

\title{
Uncovering adaptive versus acclimatized alterations in standard metabolic rate in Brown Bullhead (Ameiurus nebulosus)
}

Tood A. Leadley

University of Windsor

Anne McLeod

University of Windsor

Timothy B. Johnson

Daniel D. Heath

University of Windsor

Ken G. Drouillard

University of Windsor

Follow this and additional works at: https://scholar.uwindsor.ca/glierpub

Part of the Biochemistry, Biophysics, and Structural Biology Commons, and the Physical $\underline{\text { Sciences and Mathematics Commons }}$

\section{Recommended Citation}

Leadley, Tood A.; McLeod, Anne; Johnson, Timothy B.; Heath, Daniel D.; and Drouillard, Ken G.. (2015). Uncovering adaptive versus acclimatized alterations in standard metabolic rate in Brown Bullhead (Ameiurus nebulosus). Canadian Journal of Fisheries and Aquatic Sciences, 73 (6), 973-981.

https://scholar.uwindsor.ca/glierpub/18

This Article is brought to you for free and open access by the Great Lakes Institute for Environmental Research at Scholarship at UWindsor. It has been accepted for inclusion in Great Lakes Institute for Environmental Research Publications by an authorized administrator of Scholarship at UWindsor.

For more information, please contact scholarship@uwindsor.ca. 
1 TITLE: Uncovering adaptive versus acclimatized alterations in Standard Metabolic Rate in

2 Brown Bullhead (Ameiurus nebulosus).

4 AUTHORS: Todd A. Leadley ${ }^{\mathrm{a}}$, Anne M. McLeod ${ }^{\mathrm{a}}$, Timothy B. Johnson ${ }^{\mathrm{b}}$, Daniel Heath ${ }^{\mathrm{a}}$ and 5 Ken G. Drouillard ${ }^{a *}$

7 Author Affiliations:

$8{ }^{\text {a }}$ Great Lakes Institute for Environmental Research, University of Windsor, 401 Sunset Ave.

9 Windsor, Ontario, Canada, N9B 3P4.

$10{ }^{\mathrm{b}}$ Ontario Ministry of Natural Resources, Lake Ontario Fisheries Station, 41 Hatchery Lane,

11 R.R. \#4, Picton, Ontario, Canada, K0K 2T0. tim.johnson@ Ontario.ca

12 E-mail Addresses of authors:

13 Todd Leadley: leadley@uwindsor.ca, Anne McLeod: mcleod15@uwindsor.ca,

14 Tim Johnson: tim.johnson@Ontario.ca, Daniel Heath: dheath@uwindsor.ca,

15 Ken Drouillard: kgd@uwindsor.ca

16

17 *correspondence: Ken D. Drouillard. Great Lakes Institute for Environmental Research,

18 University of Windsor, 401 Sunset Ave. Windsor, Ontario, Canada, N9B 3P4. (519) 253-3000

19 Extension: 4744, kgd@uwindsor.ca 
21 Standard metabolic rates (SMR) were measured in Brown Bullheads collected from two

22 locations of the Detroit River, North America, representative of highly contaminated and

23 uncontaminated areas. Measurements of SMR were completed within $10 \mathrm{~d}$ of fish collections

24 (acute trials), for fish held in a common pond environment for 1 year (clearance trials) and for F1

25 generation fish raised in the pond environment (F1 study). SMRs were significantly higher

$26(26 \%)$ in fish from the contaminated area during acute trials. Both populations showed large

27 decreases in SMR (49 to $52 \%$ ) following clearance, however, differences between populations

28 were still evident. There were no significant differences in SMRs between populations for F1

29 fish. This study demonstrates that Detroit River Brown Bullheads from contaminated areas have

30 higher metabolic rates than fish from clean locations and this metabolic effect is retained for long

31 durations after fish are placed in a common environment. The loss of metabolic differences in F1

32 offspring indicates that the observed differences in SMR were acclimation based and not

33 adaptive or related to maternal effects.

34 Key Words: Brown Bullhead, Standard metabolic rate, pollution adaptation, bioenergetics 
INTRODUCTION

Standard metabolic rate (SMR) is an important component of the energy budget and represents the minimal energy required to sustain physiological function excluding consumption, digestion and activity (Enders et al. 2006). Since the SMR defines the baseline for the scope of somatic growth and reproduction in fish (Adam and Breck 1990), SMR may have strong linkages to animal fitness and can be subject to selective pressures under different environments

42 and chronic stressors/interactions (Fitzgibbon et al. 2007; Burton et al. 2011; Killen et al. 2013).

43 Further, SMRs are known to vary within populations as a result of intrinsic and extrinsic factors

44 (Norin and Malte 2012). Inherent factors such as genotype, maternal effects, early development 45 conditions and behavioural traits have all been shown to influence the energetic maintenance costs of conspecifics (Burton et. al. 2011). Extrinsic conditions are also known to cause changes

47 in fish SMR including social interactions, seasonal shifts (Beamish 1964; Sloman et al. 2000;

48 Chipps et al. 2000), photoperiod (Biswas and Takeuchi 2002), habitat (Millidine et al. 2006),

49 fish density (Reid et al. 2011), feeding activity, water quality (e.g. low dissolved oxygen concentrations and pH) (Ginnekena and Thillart 2009; Fromm 1980; Cech et al. 1985) and contaminant exposure. Despite these interactions, the common bioenergetic modelling approach

52 (e.g. Wisconsin Model) treats all individuals of a species equally and provides little opportunity

53 for adjustment to intrinsic or extrinsic variables described above. In order to improve the 54 accuracy of bioenergetic modelling applications it is necessary to improve our understanding of 55 extrinsic factor/SMR relationships by comparing SMRs among populations of fish under 56 different environmental conditions. One extrinsic factor that has been shown to directly influence metabolic rate of fish is exposure to toxic contaminants. Exposure to metals, pesticides, polycyclic aromatic 
hydrocarbons (PAHs) and persistent organic pollutants (POPs), and the subsequent metabolic

60 effects (e.g. change in $\mathrm{O}_{2}$ consumption rates) in fish have been well documented (Heath 1987;

61 Handy and DePledge 1999). For example, Waiwood and Beamish (1978) observed that for a

62 given swimming speed and $\mathrm{pH}$, Rainbow Trout (Oncorhynchus mykiss) in water dosed with copper $(25$ and $40 \mu \mathrm{g} / \mathrm{L}$ ) exhibited higher oxygen consumption rates than controls. Exposure to

64 PAHs has also been shown to affect metabolic rates of Mummichog (Fundulus heteroclitus), whereby fish exposed to PAHs in their diet (900 ng/g $\Sigma$-PAH) demonstrated a $13 \%$ increase in oxygen consumption rate relative to controls (Merten 2005). In other studies, both Largemouth

67 Bass (Micropterus salmoides) and Rainbow Trout $\mathrm{O}_{2}$ consumption rates significantly increased following exposure to elevated pesticide concentrations of dieldrin and DDT respectively (Lunn et al. 1976; Beyers et al. 1999). The above studies indicate that contaminant exposures have a bioenergetic cost on fish. Whether this effect is the result of energy allocation related to an

71 acclimated response to the stressor (Jobling 1994; Barton 2002) or the result of a direct interaction between the chemical and a biochemical pathway regulating fish metabolism (i.e. a toxic consequence of the exposure; Basha et al. 1984; Ali et al. 1993; Willet et al. 2001; Richter et al. 2011) is unknown. Long-term exposure to chemical stressors in the environment may also contribute to natural selection in exposed fish populations resulting in heritable differences in fish/stressor responses (Meyer and Di Giulio 2002, 2003; Breckels and Neff 2010; Wirgin et al.

77 2011). Adaptive responses and/or maternal effects to fish metabolic rate would be expected to 78 contribute to population differences in energy metabolism of fish, observable in offspring reared 79 outside of the environment of parental capture. To date, most investigations studying the effects of contaminants on fish SMR have been 81 performed under laboratory conditions (Macleod and Pessah 1973; Heath 1987; Beyers et al. 
82 1999). There exists limited information about how the SMRs of natural fish populations respond

83 to long-term (multi-generation) exposures to mixtures of toxic contaminants in the field. In the

84 present study, intraspecific variation of SMR was determined in two relatively isolated

85 populations (Soderberg 2013) of Brown Bullhead (Ameiurus nebulosus) inhabiting clean and

86 contaminated areas within the Detroit River. This three part study was developed to contrast

87 SMR in the two populations of fish i) immediately following capture from their natural environment (acute study), ii) following a long-term acclimation of field captured individuals to a clean aquaculture environment (clearance study) and iii) in F1 offspring derived from each

90 population (F1 study). This permitted an examination of inter-population differences in SMR

91 and attributing such responses to acclimation or heritable response/maternal effects.

MATERIALS and METHODS

Site description and fish collections

The Detroit River is a connecting channel within the Huron-Erie corridor of the

95 Laurentian Great Lakes. In 1987 the river was designated as a Great Lakes Area of Concern by the International Joint Commission owing to a series of beneficial use impairments, many being

97 related to toxic contaminants in water and sediments (Green et al. 2010). Previous sediment surveys of the Detroit River have reported widespread and elevated concentrations of PAHs,

99 PCBs, organochlorine pesticides and metals (e.g. copper, mercury, cadmium, lead, nickel and 100 zinc) within depositional zones along the south east channel of the river (e.g. Trenton Channel)

101 compared to less contaminated upstream locations (e.g. Peche Island) (Kashian et al. 2008;

102 Drouillard et al. 2006; Szalinska et al. 2007; Szalinska et al. 2013). Contamination of the lower 103 downstream reach is believed to be a long-term legacy phenomena associated with a hundred 
104 years of intense population growth and industrial activities within the region (Kauss and Hamdy 105 1985, UGLCCS 1988).

Sampling of Brown Bullheads was conducted in the above two regions, with Peche Island

$107\left(42^{\circ} 20^{\prime} 42.29^{\prime \prime} \mathrm{N}\right.$ and $\left.82^{\circ} 55^{\prime} 39.30^{\prime} \mathrm{W}\right)$ representative of the clean location and Trenton Channel

$108\left(42^{\circ} 10^{\prime} 49.01^{\prime \prime} \mathrm{N}\right.$ and $\left.83^{\circ} 09^{\prime} 09.42^{\prime} \mathrm{W}\right)$ representative of contaminant areas. In order to eliminate

109 environmental factors that may affect between-population SMR comparisons in this study,

110 sampling locations were carefully chosen to ensure that habitat between the two sites were

111 similar. This included sampling fish from sites with similar depths, cover, current, temperature,

$112 \mathrm{pH}$, dissolved oxygen concentrations, substrate, and submergent macrophtye community (i.e.

113 habitat structure) for acute trials and maintaining fish under identical pond environments for

114 clearance trials.

115 Despite inhabiting the same system, genetic evidence suggests that fish from these two 116 locations are reproductively isolated from one another (Soderberg 2013). Fish from these two 117 areas also display large differences in tissue-accumulated contaminant concentrations (Leadley et 118 al. 1998; Farwell et al. 2013). Measurements of SMR were conducted in three main study trials 119 to contrast metabolic rate of fish derived from clean and contaminated sites. The first study 120 (Acute SMR) involved measurement of SMRs in fish from clean and contaminated sites shortly 121 (within 3-10 d of collection) following their capture from the field. The second study (Cleared 122 SMR) involved measurement of SMRs in fish from the two locations after holding the fish in 123 mesocosm ponds at an aquaculture facility for a period of 1 year. The third study (F1 SMR) 124 involved measurement of SMR in offspring of the cleared fish used in study 2. Experimental 125 conditions for each sub-study are outlined in greater detail below. All studies described were 
126 performed following ethical review and approval from the local animal care committee at the

127 University of Windsor in compliance with the Canadian Council for Animal Care guidelines.

Detroit River Brown Bullheads were collected from July through September 2009 to

129 generate fish for long-term holding for Cleared and F1 studies. Fish were collected using a 5

130 meter single boom electrofishing vessel equipped with a $5 \mathrm{~kW}$ generator. Two bow netters

131 retrieved stunned fish as they appeared and the collected fish were immediately transferred to

132 onboard aerated live wells for positive identification and recovery. A total of 50 Brown

133 Bullheads with a wet mass ranging from 163 - $495 \mathrm{~g}$, were collected from Trenton Channel

134 followed by 53 Brown Bullheads from Peche Island with a wet mass ranging from $113-495 \mathrm{~g}$.

135 Fish from each sampling location were rapidly transferred to a nearby fish farm in Essex, Ontario

136 where they were released into separate earthen ponds (mesocosms) following a 30-minute

137 acclimation period. These semi natural mesocosms each measured approximately $140 \mathrm{~m}^{3}(\mathrm{~L} 12.5$

$138 \mathrm{~m} \times \mathrm{W} 7.5 \mathrm{~m} \times \mathrm{D} 1.5 \mathrm{~m}$ ) and were supplied with continuous $24 \mathrm{~h}$ aeration year round. The

139 bullheads were held in the mesocosms for a period of one year and allowed to spawn naturally

140 the following spring.

Between July and October 2010 both river locations were re-sampled in order to collect

142 bullheads for the acute SMR study. Post reproductive Bullheads were collected as described

143 above and then quickly transferred to indoor holding facilities. A total of 21 bullheads with a wet

144 mass ranging from 119-495 g were collected from Trenton Channel and 23 bullheads with a wet

145 mass ranging from 113-399 g were collected from Peche Island. Fish were held in tanks as

146 detailed below and SMR measurements were conducted on each individual in the acute trial

147 following a brief tank acclimation of $24-48 \mathrm{~h}$ to ensure clearance of the gastrointestinal (GI) tract. 
All SMR measurements were performed using a single chamber intermittent flow

respirometer (Loligo Systems; DAQ-PAC-G1S) controlled through AutoResp ${ }^{\mathrm{TM}} 1$. The typical configuration for the respirometer requires the fish be placed in a closed respirometer chamber which is then immersed in an ambient tank where two small recirculation pumps move water through the system during the computer controlled flush and measurement periods. This configuration was modified with the addition of a $950 \mathrm{~L}$ freshwater tank in combination with the ambient tank. The extra tank provided a location to connect inline heating and chilling units as well as a place for air stone placement (i.e. aeration) away from the ambient tank. A submersible water pump was used to provide a continuous flow of fresh water to the ambient tank where the respirometer chamber was located. This set up ensured a more stable system in terms of maintaining saturated dissolved oxygen concentrations, temperature and overall water quality while also minimizing vibration and noise.

To obtain reliable estimates of oxygen consumption rate, three sizes of respirometry chambers were used in the study. A large sized chamber (volume $=2924 \mathrm{~mL}$ ) was used for bullheads in the size range of $200+\mathrm{mm}$, a medium sized chamber (volume $=1133 \mathrm{~mL}$ ) was used for bullheads in the size range of $150-200 \mathrm{~mm}$ and a small chamber (volume $=196 \mathrm{~mL}$ ) was used for bullheads that were less than $100 \mathrm{~mm}$ (mainly trial 3; F1 offspring fish). Prior to placement in the respirometry chamber, fish were sedated by immersion in an aerated $20 \mathrm{~L}$ pail with MS-222 (50 mg/L) buffered with sodium bicarbonate. Once the fish was unresponsive, it was removed and measured for total length $(\mathrm{mm})$, mass $(\mathrm{g})$ and volume (L; via water displacement). The data on fish mass and volume was entered into the respirometry software, the respirometer was set to a constant flush cycle and the fish was placed in the chamber and allowed to recover. When the fish demonstrated signs of recovery, all air bubbles were removed 
172 from the chamber and the respirometry computer program was initialized. Flush and

173 measurement cycles (typically 400 and 375 seconds respectively) were adjusted to ensure that

174 oxygen levels remained near saturation in the chamber during the measurement cycle when the

175 chamber was sealed. SMR measurements were taken for each fish over a 12-24 h period. All

176 measurements were taken under low light conditions by covering the ambient tank. Since the

177 respirometer used was a single chamber design, only one fish SMR was recorded at a time. In

178 order to correct for oxygen consumption that occurs from the natural build-up of microbial

179 biomass within the respirometer system (Grottum and Sigholt 1998; Clark et al. 2013) blank

180 measurements (i.e. trial runs with no fish) were conducted at the end of each study run. The

181 resulting mean $\mathrm{O}_{2}$ consumption value of blanks was subtracted from the fish $\mathrm{O}_{2}$ consumption

182 value of each study trial.

Across fish, heightened oxygen consumption rates were commonly observed during the

184 first $4 \mathrm{~h}$ after initiating the AutoResp ${ }^{\mathrm{TM}} 1$ computer program. This was interpreted as stress 185 associated with handling, sedation recovery and initial response of fish to confinement. As a 186 general rule, all readings from the first $4 \mathrm{~h}$ of measurement were censored from consideration in 187 the evaluation of SMR. Fish $\mathrm{O}_{2}$ consumption profiles typically show variable periods in the rate 188 of $\mathrm{O}_{2}$ consumption as opposed to a steady consumption rate (Steffensen 1989). For the 189 calculation of SMR, only measurements that occurred within the $25^{\text {th }}$ and $75^{\text {th }}$ percentile during 190 the post $4 \mathrm{~h}$ measurement period were considered. This was done to exclude spontaneous periods 191 of high or low $\mathrm{O}_{2}$ consumption. The high values were attributed to acute periods of routine 192 metabolism (i.e. spontaneous activity) (Steffenson 1989). Abnormally low values were attributed 193 to either a brief change in the metabolic rate of the fish (e.g. hypometabolism, hypoventilation) 194 or irregular sensor readings resulting in abnormally low and invalid $\mathrm{O}_{2}$ consumption 
measurements (Clarke et al. 2013). Selected respirograms, reflecting raw $\mathrm{O}_{2}$ consumption measurements with time for an individual fish are presented in Figure 1. Only measurements post $4 \mathrm{~h}$ of experiment initiation (left of vertical line) and within the $25-75$ percentile distribution (horizontal dashed lines) were used to generate a mean SMR value for each fish used in the studies.

\section{Study 1 (Acute SMR)}

Following field collections, fish designated for the acute SMR study were transferred to a $7000 \mathrm{~L}$ indoor tank equipped with a recirculating bio-filtration unit that included supplemental aeration and three 120 Watt UV sterilizers. The holding tank water temperature was equivalent to the river temperature. Acute fish were brought from the field in batches, placed in coolers containing water from their site of capture. The coolers were then suspended in the holding tanks, and tank water was slowly added over of period $2 \mathrm{~h}$. When the water was fully renewed in the cooler, it was fully immersed allowing the fish to swim freely out of the cooler. The exact same procedure was used in the case of field and pond held fish which were being collected over the same time frame.

Submerged open-ended $600 \mathrm{~mm}$ by $76 \mathrm{~mm}$ potable PVC pipes were added to the tanks as refuges for fish and the ambient tank was covered with an opaque lid to reduce overhead light and eliminate external room shadows. Following acclimation, the SMR of fish of both clean and contaminated origin were measured at $23^{\circ} \mathrm{C}(12-24 \mathrm{hr}$ trial runs) using the respirometer as described above. The acute SMR trials were started immediately following the initial $48 \mathrm{hr}$ fast and conducted on individual fish from July 27 through November 12010 . Depending upon collection success on a particular sampling day, an unavoidable time lag occurred between the 
218 time of collection for some bullheads and the start of their SMR measurements (i.e. some fish

219 remained in the holding tank longer than others). Most fish were assessed within 5 days of

220 collection from the field to a maximum of 10 days. The SMR of each fish was measured only

221 once.

222 Study 2 (Cleared SMR)

223 Fish collected for the long-term holding investigation were placed in two separate

224 outdoor $\sim 140 \mathrm{~m} 3$ earthen ponds. The fish were kept in the uncontaminated mesocosms for a

225 period of one year (July 2009 to July 2010) under natural photoperiod and temperature

226 conditions. The ponds were supplied with continuous aeration year round and fish were

227 provisioned with a maintenance ration of fish pellets recommended for cool water fish (Martin

228 Mills Inc.). Bullheads were not fed pellet rations when pond temperature fell below $8^{\circ} \mathrm{C}$.

Basic water quality conditions were periodically assessed within each of the ponds to

ensure dissolved $\mathrm{O}_{2}, \mathrm{pH}$, and temperature were within acceptable ranges for the health of the fish

231 and to ensure that water quality between the ponds remained within similar ranges. Basic water

232 quality parameters were measured in situ using a Hydrolab Surveyor 3/ Reporter multiparameter

233 water quality logging system.

The removal of these fish from their original sources of contaminant exposure (i.e.

235 sample locations) and subsequent yearlong holding into an uncontaminated system allowed

236 accumulated contaminants in the fish to be depurated. Consequently Study 2 bullheads are

237 hereafter referred to as "cleared" in reference to the long-term contaminant depuration of these

238 fish in the holding ponds (for a description of reductions in persistent organic pollutant burdens

239 measured in pond held fish see Farwell et al. 2012 and data in Table 1). 
Following the holding period, the bullheads were removed from both ponds and

241

242

243

244

245

246

247

248

249

250

251

252

253

254

255

256

257

258

259

260

261

transferred to a $7000 \mathrm{~L}$ indoor tank (identical to those used in Study 1) according to the same

procedure used in acute trials. Water temperatures were maintained at $23^{\circ} \mathrm{C}$ during measurement and all fish were acclimated to the new tank for 72 hours before SMR measurements

commenced. Similar to Study 1, all fish were fasted for $48 \mathrm{~h}$ prior to placement in the chamber and individual measurements were taken over a 12-24 h period. Fish from different treatments were measured in an alternating fashion across SMR trials periodically interrupted for completing acute SMR (Study 1) trials as fish were collected. SMR measurements for all Study 2 fish commenced July 272010 and were completed November 12010.

\section{Study 3 (F1 SMR)}

The study 2 fish residing in the two treatment ponds spawned naturally during the spring of 2010. Schools of young bullhead, hereafter designated as F1 fish, were observed in both ponds during late June 2010. The F1 fish were allowed to grow out in each of the parental ponds and were not sampled until they reached a mean mass of $\sim 20 \mathrm{~g}$. During the grow out period, the F1 fish were provided Silver Cup® starter feed in addition to the ration provided to adult fish, as well as naturally occurring forage. In mid-August, $17 \mathrm{~F} 1$ fish from the Peche Island pond and 8 fish from the Trenton Channel Pond were collected and transferred to the $7000 \mathrm{~L}$ indoor tanks (water temperature of $23^{\circ} \mathrm{C}$ ) used for holding fish in Study 1 and 2 during SMR measurements.

The low numbers of F1 fish retrieved from the ponds were not a result of low survivorship but a result of other projects making use of these F1 fish for other research trials. The SMR measurements of individual fish followed the same protocol as described for the previous Study 1 and 2 with the exception of utilizing a smaller respirometry chamber (volume $=196 \mathrm{~mL}$ ) to 
262 increase the sensitivity of the respirometry measurements. A total of 25 measurements were

263 taken for F1 fish from the two treatment groups between August 17 and September 302011.

264 Data Analysis

265 Prior to analysis, assumptions of data normality and heteroscedacitity were tested using Shapiro-

266 Wilk normality test and Levene's Test for homogeneity of variance. Non-normal data were log

267 transformed and re-tested to ensure assumptions of analysis of variance were met. A general

268 linear model (GLM) was used to test treatment differences as well as all combinations of

269 treatment interactions in a 2 x 3 design whereby:

$270 \log \mathrm{SMR}=\log \mathrm{BW}+$ Population + Treatment $+\log \mathrm{BW} *$ Population + Log BW * Treatment

$271+$ Treatment $*$ Population $+\log$ BW * Treatment $*$ Population + Constant

272 In the above model, BW is fish body mass $(\mathrm{g})$ measured for each fish tested, population is a

273 categorical variable corresponding to fish origin (or parental origin) and treatment is categorical

274 variable corresponding to the three experimental trials: Acute, Cleared or F1 trials. Following

275 initial model evaluation it was observed that body mass had a highly significant effect on SMR

$276(\mathrm{~F} 1,85=27.67 ; \mathrm{p}<0.001)$ as expected from known allometric relationships between body size

277 and fish metabolic rate. However, all interaction terms involving body mass were found to be

278 non-significant (Population $* \mathrm{BW}, \mathrm{F}_{1,85}=1.375, \mathrm{p}>0.2$; Treatment $* \mathrm{BW}, \mathrm{F}_{2,85}=1.072, \mathrm{p}>0.3$

279 and Population * Treatment $\left.* \mathrm{BW}, \mathrm{F}_{2,85}=0.792, \mathrm{p}>0.4\right)$. This indicated that each population and

280 treatment exhibited similar allometry of SMR with respect to body size. Subsequently, analysis

281 of covariance was performed using $\log \mathrm{BW}$ as a co-variate within the $2 \mathrm{x} 3$ factorial design by

282 removing the interaction terms involving BW according to:

$283 \log \mathrm{SMR}=\log \mathrm{BW}+$ Population + Treatment + Treatment $*$ Population + Constant 
284 In this case, the $\mathrm{R}^{2}$ of the second model showed only a small decrease in explanatory power $\left(\mathrm{R}^{2}\right.$ 285 of model 1 was 0.89 while the $\mathrm{R}^{2}$ of model 2 was 0.87 ) and both model I and II exhibited similar 286 Akaiki Information Criteria (AIC) values at -221.3 and -221.9, respectively. Given the large size 287 differences between treatments, especially since F1 fish which were much smaller than acute or 288 cleared fish, Model II was considered the more appropriate method for testing main effects. 289 Following interpretation of the main effects, a posteriori tests (Tukeys HSD) were used to 290 examine differences between SMR for each combination of population and treatment. All 291 statistical tests were completed using SYSTAT 13 statistical software. For data summary 292 purposes, SMRs were size corrected to a standard $200 \mathrm{~g}$ fish based on the slope generated for log 293 BW (-0.336) from model 2 such that:

$$
S M R_{S S}=\frac{\log (-0.336 \cdot B W)}{\log (-0.336 \cdot 200)} \cdot S M R
$$

295 Throughout the text means and standard errors (SE) are reported for variables that exhibited 296 normal distribution, while geometric means and 95\% confidence intervals are reported for 297 variables that exhibited log normal distributions

298 RESULTS

Bullhead mortalities soon after the transfer to the outdoor mesocosms were observed in

300 both ponds ( $\mathrm{TR}=2$ fish and PI $=1$ fish $)$ and attributed to collection and transfer stress. No

301 bullhead deaths were recorded in the facility's large holding tanks during the pre SMR holding 302 period, but two Trenton Channel bullheads (TR) deaths occurred during the SMR trials in the 303 respirometer chamber due to a flush pump failure. Data from these trials were excluded. 
Bullheads in each pond began accepting pellet food within 7 days following the transfer from their respective river locations. Pond water quality remained within acceptable guidelines (CCME 1999) throughout the holding period ( $\mathrm{DO}>6 \mathrm{mg} \cdot \mathrm{L}^{-1}, \mathrm{pH} 7.2$ to 7.6 ). Pond temperatures increased and decreased naturally following seasonal progression. In order to avoid excessive pond warming during peak summer months, aerators were placed in the shallow areas of the ponds to avoid complete mixing of the entire pond thereby allowing bottom waters to remain cooler. Winter aeration allowed for the exchange of gases preventing potential winterkill (Lynch and Norland 2001). No winter mortalities were noted for either pond.

Data on body size, sample numbers and raw standard metabolic rate (uncorrected for fish size) are presented in Table 1. The GLM Model II fit to the data explained $87 \%$ of the variation across treatments and populations. There were highly significant differences between SMRs for the two populations $\left(\mathrm{F}_{1,90}=12.7 ; \mathrm{p}<0.001\right)$; highly significant differences between the three treatments $\left(\mathrm{F}_{2,90}=145.4 ; \mathrm{p}<0.001\right)$ and significant differences among SMRs for the treatment $\mathrm{x}$ population interaction $\left(\mathrm{F}_{2,90}=6.5 ; \mathrm{p}<0.01\right)$. In order to demonstrate GLM Model II fits, uncorrected SMR data are expressed against fish body mass for each experimental group in Figure 2 along with predictions generated from the GLM Model II. GLM model predictions were strongest for Peche Island Acute and Cleared trials, while data for F1 showed poorer allometric response, mainly due to the limited size range of fish tested in that trial. Model predictions also tended to underestimate SMR for Trenton Channel acute and cleared fish relative to actual measurements (Figure 2).

Figure 3 presents a comparison of size corrected SMR data for PI and TC fish from each of the three experimental studies. For Study 1 (Acute SMRss), the mean and 95\% confidence interval SMRss of PI fish was $80.7 \mathrm{mg} \mathrm{O} 2 \cdot \mathrm{kg}^{-1} \cdot \mathrm{hr}^{-1}$ (95\% CI: 73.5 to $88.5 \mathrm{mg} \mathrm{O} \cdot \mathrm{kg}^{-1} \cdot \mathrm{hr}^{-1}$ ) and 
327 was significantly ( $\mathrm{p}<0.001$; Tukey's HSD) lower than TC fish $\left(100.7 \mathrm{mg} \mathrm{O} \mathrm{Og}^{-1} \cdot \mathrm{hr}^{-1} ; 95 \% \mathrm{CI}\right.$ :

32895.0 to $106.8 \mathrm{mg} \mathrm{O} \cdot \mathrm{kg}^{-1} \cdot \mathrm{hr}^{-1}$ ). This corresponded to a between population difference in $\mathrm{SMR}_{\mathrm{ss}}$

329 of $19.9 \%$. In Study 2 (Cleared SMR $\mathrm{ss})$, the mean and 95\% CI SMR $\mathrm{ss}$ of PI fish $\left(38.5 \mathrm{mg} \mathrm{O}_{2} \cdot \mathrm{kg}^{-}\right.$

$330{ }^{1} \cdot \mathrm{hr}^{-1}$; 95\%CI: 36.0 to $41.1 \mathrm{mg} \mathrm{O}_{2} \cdot \mathrm{kg}^{-1} \cdot \mathrm{hr}^{-1}$ ) was significantly lower (Tukey’s HSD; $<<0.001$ )

331 than TC fish $\left(50.1 \mathrm{mg} \mathrm{O} 2 \cdot \mathrm{kg}^{-1} \cdot \mathrm{hr}^{-1} ; 95 \% \mathrm{CI}: 43.1\right.$ to $\left.58.3 \mathrm{mg} \mathrm{O} \cdot \mathrm{kg}^{-1} \cdot \mathrm{hr}^{-1}\right)$. In this case, the

332 between population difference in SMR was 23.2\%. Notably, the SMR of cleared fish from each

333 population showed a decrease in SMR values compared to acute fish from each population. PI

334 fish showed a 52.3\% decrease in SMR of cleared fish relative to acute fish. Similarly, TC fish

335 exhibited a 50.2\% drop in SMR of cleared compared to acute fish. For Study 3 (PI and TC F1

$336 \mathrm{SMR}_{\mathrm{SS}}$,), the mean and 95\% CI SMR $\mathrm{sS}$ for TC F1 offspring $\left(69.6 \mathrm{mg} \mathrm{O}\right.$ oxygen $\cdot \mathrm{kg}^{-1} \cdot \mathrm{hr}^{-1}$;

$33795 \% \mathrm{CI}$ : 60.8 to $79.7 \mathrm{mg} \mathrm{O} \cdot \mathrm{kg}^{-1} \cdot \mathrm{hr}^{-1}$ ) was not significantly different ( $\mathrm{p}>0.9$; Tukey's HSD) from

338 PI F1 fish $\left(73.5 \mathrm{mg} \mathrm{O}{ }_{2} \cdot \mathrm{kg}^{-1} \cdot \mathrm{hr}^{-1}\right.$; 95\%CI: 67.5 to $\left.80.0 \mathrm{mg} \mathrm{O} \cdot \mathrm{kg}^{-1} \cdot \mathrm{hr}^{-1}\right)$. However, F1 fish did

339 show generally higher size corrected SMRss relative to cleared fish. The PI acclimated fish had

340 significantly $(\mathrm{p}<0.01$; Tukey’s HSD) lower SMR SS compared to PI F1 fish, but were not

341 significantly different ( $\mathrm{p}>0.05$; Tukey’s HSD) from TC F1 fish. TC cleared fish were not

342 significantly ( $>0$ 0.9; Tukey's HSD) different from TC F1 fish or PI F1 fish ( $p>0.6$; Tukey’s

343 HSD). In contrast, acute fish from each treatment group were significantly higher than fish

344 across all other groups from both cleared and acute trials. These observations provide a general

345 indication that cleared and F1 fish approached one another with respect to overall SMR

346 compared to acute fish which consistently showed the highest size corrected SMR

347 measurements. 
The results of Study 1 (Acute SMR) are consistent with the initial hypothesis that Brown

351 Bullheads collected from contaminated regions within the Detroit River exhibit increased SMRSS

352 compared to fish collected from less contaminated areas. Of interest was that the significant

353 difference in SMRss between the two populations persisted following a one year period where

354 fish from the two populations were placed in a common clean low/stress environment (Study 2

355 cleared SMR). Whether or not the between population differences in SMRSS represent permanent 356 changes to SMR of examined fish or if between population differences in SMR are capable of 357 being lost after longer holding periods is not known.

The two acute collection locations were chosen to represent gradients in river contamination for pollutants such as PAHs known to contribute to altered metabolic rates of fish

360 (Heath 1987; Handy and DePledge 1999; Merten 2005). Sediment contamination for organic 361 and metal contaminants at TC has been known to be enriched relative to upstream areas of the 362 Detroit River since at least the 1970's and the sediment chemistry related to PCBs, PAHs, OC363 pesticides, mercury and metals was shown to have been stable for the past 10 years (Drouillard et 364 al. 2006; Szalinska et al. 2013). These differences in sediment chemistry translate into different 365 chemical exposures for biota within the system. PCBs and PAHs in caged mussels sampled from 366 the TC and PI (Gewurtz et al. 2002; Drouillard et al. 2013) showed notably higher contamination 367 at TC compared to the up river reference location in the vicinity of PI. Past studies further 368 reported that bullheads from PI and TC exhibited significant differences in contaminant 369 exposures to PCBs, PAHs and organochlorine compounds (e.g. DDD, DDE, DDT, heptachlor; 370 chlorinated benzenes) (Leadley et al. 1998, 1999). Notably, Farwell et al (2012) measured PCB 371 residues in eggs generated by a subset of acute and cleared TC and PI fish used concurrently 372 with the present study. The data from the above study is presented in Table 1. Results show that 
373 eggs from acute TC fish contained 7.6 fold higher total PCB concentrations compared to PI fish

374 ova. Following one year of clearing in the mesocosms, both fish populations decreased their

375 PCB concentrations by approximately 52 and $49 \%$ for TC and PI fish, respectively. However,

376 cleared TC fish in that study still contained higher concentrations than PI fish post clearing.

377 Unfortunately, we did not measure PCBs in F1 fish from this study. However, F1 fish of similar

378 size from an alternate population (derived from Bay of Quinte, Lake Ontario) reared in the same

379 ponds under the same conditions were analyzed. The alternate population F1 fish had sum PCB

380 concentrations that were 50\% and 30\% lower than acute and cleared fish, respectively (Table 1).

381 Thus, the somewhat higher SMRss of F1 fish relative to cleared fish is not likely a result of PCBs

382 levels in F1's.

In general, the between population differences in SMRss observed for acute and cleared

384 fish from the present research is consistent with the magnitude of SMR alterations shown to be 385 induced under laboratory conditions after exposing fish to various contaminants. For example,

386 Merten et al. (2005) exposed Mummichog to a gradient of PAH contaminated food and observed 387 a significant increase in Mummichog SMRs following exposure (120+ days) to a diet

388 contaminated with PAHs (2800 ng/g w/w). Conversely, the Mummichog SMRs were depressed 389 at $10 \%$ concentrations (840 ng/g w/w) compared to control fish. Beyer et al. (1999) observed a 390 similar result in Largemouth Bass (Micropterus salmoides) where routine metabolic rates 391 initially decreased following an acute (1-4 day) exposure to the pesticide dieldrin but increased 392 significantly over time (16 days) with increasing exposure concentrations. Similar responses 393 have also been shown to occur in fish following exposure to metals. For example, the SMR of 394 fathead minnows and golden shiners both decreased following an acute exposure (24h) to 395 cadmium and copper, where longer exposures (>96h) resulted in elevated SMRs in both species 
(Pistole et al. 2008; Peles et al. 2012). In the above case, the SMR of golden shiners exposed to the two treatments concentrations of 200 and $500 \mu \mathrm{g} \cdot \mathrm{L}^{-1} \mathrm{Cd}$ for $96 \mathrm{~h}$ increased by $65 \%$ compared to the control fish (Peles et al. 2012). These studies and several others support a metabolic cost for fish chronically exposed to multiple chemical stressors in the environment (Hopkins et al. 1999, Calow and Sibly 1990; Calow 1991; Rowe, 2003).

However, not all potentially toxic chemicals encountered by fish in the natural environment result in altered SMRs. For example, despite laboratory studies demonstrating a 16.7 percent increase in the SMR of Mosquitofish exposed to $100 \mu \mathrm{g} / \mathrm{L}$ of mercury for $48 \mathrm{hrs}$ (Tatara et al. 2001), no metabolic rate differences were observed in Mosquitofish with elevated body burdens of mercury and sampled from pre $\mathrm{Hg}$ dosed mesocosms compared to an uncontaminated reference population (Hopkins et al. 2003). In another study, Lake Chubsuckers (Erimyzon sucetta) exposed to coal ash-polluted sediments for 4 months had significantly elevated body burdens of Se, Sr, and V but no detectable differences in SMR, although increased mortality and significantly reduced growth rates demonstrated a bioenergetics cost experienced by exposed populations (Hopkins et al. 2000).

Following the clearance period in outdoor mesocosms, both TC and PI fish showed decreases in their SMRSS (52\% and $49 \%$ respectively) relative to acute fish from the same respective population. Notably, these within population differences in SMRss pre- and postclearance were more than 2 fold greater than the between population differences observed in either study. Differences in $\mathrm{SMR}_{\mathrm{SS}}$ between acute and cleared fish from the same populations were observed even though both groups exhibited similar size ranges and were measured at the same time owing to the staggered collection of fish used in acclimation trials and fish used for acute trials. This implies that a much broader set of extrinsic factors were influencing the SMR 
419 of fish, beyond those of tissue burdens of POPs compounds such as measured for PCBs

420 (Farewell et al. 2012). Conditions other than exposure to environmental contaminants such as

421 changes in diet and diet abundance, the presence and complexity of in-stream structural habitat,

422 water quality (e.g. dissolved $\mathrm{O}_{2}$ concentrations), presence of conspecifics and social effects such

423 as aggression and dominance have all been correlated with SMR in fish (Cech 1985; Lahti et al.

424 2002; Millidine et al. 2009; Biro and Stamps 2010; Burton et al. 2011).

Certainly a quiescent pond environment with ample food and change in diet that includes conditions of low predation risk, limited shelter and only the presence of conspecifics in a

427 limited space represents a significant environmental change compared to the riverine system

428 where the cleared fish were collected. Based on the wide range of extrinsic factors that are 429 known to affect SMRs in fish, it is plausible that a non-adaptive response to the change in the 430 environment may be in large part responsible for the decline in SMR that was observed in both 431 cleared TC and PI populations. For example, a case for altered SMR based on the habitat 432 complexity provided through artificial cover was demonstrated by Millidine et al. (2006), where 433 the addition of shelter led to a 31\% reduction in the mean SMR of Atlantic salmon parr (Salmo 434 salar) compared to parr that were measured without shelter. In another more recent study, 435 phenotypic plasticity in SMR has been shown to occur in Guppies (Poecilia reticulate) in 436 response to a change in environment, particularly in the presence and absence of predator cues 437 (Handelsman et al. 2013). Support for this non-adaptive response argument from the present research was that the 439 population differences in $\mathrm{SMR}_{\mathrm{SS}}$ were found to be lost in Study 3 which involved rearing F1 440 offspring from TC and PI populations in a common environment. To our knowledge this is the 441 first study to investigate the change in standard metabolic rates of fish populations following 
442 acclimation to a common environment and in F1 offspring generated from the two populations.

443 This enables rejection of the hypothesis that the population differences measured in SMR $\mathrm{SS}$

444 generated in study 1 and 2 reflect a local adaptation of fish from the two collection regions.

445 Adaptation to chemical exposure has been demonstrated to occur across other traits in Brown

446 Bullhead (Williams 2014) and other fish species (Rowe 2003; Hopkins et al. 2003). For example,

447 fish collected from waters near cotton fields in Mississippi with a long exposure history of

448 treatment with chlorinated hydrocarbon pesticides exhibited a marked resistance to DDT

449 compared with fish sampled from areas with no past exposure to these chemicals (Bradleigh et

450 al. 1963). Study three also rules out maternal factors (either maternal offloading of contaminants

451 or other maternal factors) as a potential modifier of SMR in the study system.

The results of this investigation demonstrate that fish from contaminated environments in

453 the Detroit River maintain elevated SMRs in comparison to fish inhabiting less contaminated

454 sites within the same riverine system. These metabolic effects persist in fish after removing them

455 from the contaminated environment over periods as long as one year. The results support a

456 general acclimation syndrome response (Selye 1956; modified by Beyer et al. 1999), whereby

457 the energy expenditure in an organism changes over time in order to compensate for the effects

458 of an encountered stressor. Following this conceptual progression, altered SMRs and/or other

459 metabolic costs expenditures (e.g. specific dynamic action) occur during the resistance stage in

460 the syndrome where physiological compensation for the effects of the stressor(s) becomes part of

461 the daily bioenergetic cost of living for the exposed animal (Beyer et al. 1999). However, it is

462 clear from this study that SMR as a physiological parameter is highly sensitive to a wide array of

463 extrinsic factors. Notably the change of environment during clearing trials would appear to have

464 had a large effect on SMR measurements, and thus the exact nature of the stressor(s) and stressor 
465 interactions responsible for population differences in bullhead SMRs cannot be directly

466 identified.

467

468

469

470

471

472 elevated energetic costs of polluted fish. However, in this case, the increased metabolic costs

473 also included additional foraging costs due to pollutant induced reductions in prey. Notably,

474 differences in SMR resulting from a combination of environment and pollution effects were

475 observed to approach the magnitude of activity multipliers commonly used to convert SMR to a

476 routine metabolic rate $(\mathrm{RMR})$ estimate in bioenergetic models (Hanson et al. 1997; Brigs and

477 Post 1997). Commonly, any differences in routine metabolic rate of fish as measured by in-situ

478 methods are interpreted to largely represent differences in fish activity (see Sherwood et al.

479 2000). However, these observations support a growing body evidence that substantive

480 intraspecific variation in SMRs exist within and among fish populations of the same species and

481 more importantly that such differences can be sustained within a connected aquatic system

482 (Burton et al. 2011). The results have implications for bioenergetics modelling applications

483 where all individuals of a species are treated similarly with respect to SMR. Additional research

484 aimed at generating a scope for environment or pollutant-induced SMR shifts in other species,

485 similar to the scope of activity concept, would be useful to further expand the accuracy of fish

486 bioenergetics models. 
488 Acknowledgement—We thank Mike Burtnyk, Michelle Farwell and Linda Söderberg for help 489 with field collections and Mike Thibert for laboratory assistance. The present study was funded

490 by a National Sciences and Engineering Research Council of Canada Strategic Project Grant and 491 the University of Windsor. All research was conducted in accordance with the principles and 492 guidelines of the Canadian Council on Animal Care.

493

494

495 References

496

Adams, S. M., \& Breck, J. E. (1990). Bioenergetics. Methods for fish biology. American

497 Fisheries Society, Bethesda, Maryland, 389-415.

498

Ali, F., Lazar, R., Haffner, D. and Adeli, K. 1993. Development of a rapid and simple

499 genotoxicity assay using a Brown Bullhead fish cell-line: application to toxicological surveys of

500 sediments in the Huron-Erie corridor. J. Great Lakes Res. 19: 342-351. doi: 10.1016/S0380-

$501 \quad 1330(93) 71222-8$.

Barton, B.A. 2002. Stress in fishes: A diversity of responses with particular reference to

503 changes in circulating corticosteroids. Integ. Comp. Biol. 42: 517-525. doi:10.1093/icb/42.3.517.

504 Basha, S. M., Prasada Rao, K. S., Sambasiva Rao, K. R. S. and Ramana Rao, K. V.

505 1984. Respiratory potentials of the fish (Tilapia mossambica) under Malathion, Carbaryl and

506 Lindane intoxication. Bull. Environ. Contam. Toxicol. 32: 570-574. doi 10.1007/BF01607539. 
Beamish, F.W.H. 1964. Respiration of fishes with special emphasis on standard oxygen

508

509

510

511

512

513

514

consumption. II. Influence of weight and temperature on respiration of several species. Can. J. Zool. 42:177-188.

Beyers, D.W., Rice, J.A., Clements, W.H. and Henry, C.J. 1999. Estimating

physiological cost of chemical exposure: integrating energetics and stress to quantify toxic effects in fish. Can. J. Fish. Aquat. Sci. 56: 814-822. doi: 10.1139/f99-006.

Biro, P.A. and Stamps, J.A. 2010. Do consistent individual differences in metabolic rate promote consistent individual differences in behaviour? Trends Ecol. Evol.. 25: 653-659.

Biswas, A.K. and Takeuchi, T. 2002, Effect of different photoperiod cycles on metabolic rate and energy loss of fed and unfed adult tilapia Oreochromis niloticus: Part II. Fish. Sci. 68: 543-553. doi: 10.1046/j.1444-2906.2002.00460.x.

Bradleigh V. S., Boyd, C.E. and Ferguson, D.E. 1963. Resistance to DDT in the Mosquito Fish, Gambusia affinis. Sci. News 139:217-218.

Breckels, R.D. and Neff, B.D. 2010. Pollution-induced behavioural effects in the Brown Bullhead (Ameiurus nebulosus). Ecotoxicology. 19:1337-1346. doi 10.1007/s10646-010-0520-1.

Burton, T., Killen, S.S., Armstrong, J.D. and Metcalfe, N.B. 2011. What causes intraspecific variation in resting metabolic rate and what are its ecological consequences? P. Roy. Soc. Lond. B. Bio. 278: 3465-3473 doi: 10.1098/rspb.2011.1778.

Calow, P. and Sibly, R. M. 1990. A physiological basis of population processes: ecotoxicological implications. Funct. Ecol. 4: 283-288. doi: 0.2307/2389587. 
Calow, P. 1991. Physiological costs of combating chemical toxicants: ecological implications. Comp. Biochem. Physiol. C. 100: 3-6. doi: 10.1016/0742-8413(91)90110-F.

http://www.ccme.ca/publications/ceqg_rcqe.html_(accessed August 2 2014).

Cech, J.J. Jr., Massingill, M.J., Vondracek, B. and. Linden, A.L. 1985. Respiratory

532 metabolism of mosquitofish, Gambusia affinis: effects of temperature, dissolved oxygen, and sex 533 difference. Env. Biol. Fish. 13: 297-307. doi: 10.1007/BF00002914. metabolism of juvenile muskellunge: evidence for seasonal metabolic compensation in fishes. J. Fish. Biol. 56: 311-318. doi: 10.1006/jfbi.1999.1156. 538 an era of climate change: respirometry, relevance and recommendations. J. Exp. Biol. 216: 2771539 2782, doi: 10.1242/jeb.084251.

541 Polychlorinated Biphenyls (PCBs), Polycylic Aromatic Hydrocarbons (PAHs), and selected 542 organochlorine pesticide residues in sediments of the Detroit River-1999. J. Great Lakes Res. 32: 209-226. doi:10.3394/0380-1330(2006)32[209:ARSOPB]2.0.CO;2. 
Enders, E.C., Boisclair, D., Boily, P. and Magnan, P. 2006. Effects of body mass and

water temperature on the standard metabolic rate of juvenile yellow perch (Perca flavescens).

Environ. Biol. Fish. 76: 399-407.

Farwell, M. 2012. Evolutionary toxicology: Implications of polychlorinated biphenyls in fishes from the lower Great Lakes. PhD Thesis. Department of Biology, University of Windsor, Windsor, Ontario, Canada. Electronic Theses and Dissertations. Paper 4803.

Farwell, M., Drouillard, K. G., Heath, D. D., \& Pitcher, T. E. (2013). Associations

between female reproductive traits and polychlorinated biphenyl sediment concentrations in wild populations of brown bullhead (Ameiurus nebulosus). Arch. of Environ. Contam. and Toxicol., 65:,742-752.

Fitzgibbons, Q.P., Strawbridge, A. and Seymoura, R.S. 2007. Metabolic scope, swimming performance and the effects of hypoxia in the mulloway, Argyrosomus japonicus (Pisces: Sciaenidae). Aquaculture. 270: 358-368. doi: 10.1016/j.aquaculture.2007.04.038.

Fromm, P. O. 1980. A review of some physiological and toxicological responses of freshwater fish to acid stress. Environ. Biol. 5: 79-93. doi: 10.1007/BF00000954.

Gewurtz, S.B., Lazar, R. and Haffner, G.D. 2003. Biomonitoring of Bioavailable PAH and PCB Water Concentrations in the Detroit River Using the Freshwater Mussel, Elliptio complanata. J. Great Lakes Res. 29: 242-255. doi: 10.1016/S0380-1330(03)70430-4.

Ginnekena, V.V. and Thillart, G.V.D. 2009. Metabolic depression in fish measured by direct calorimetry: A review Thermochim. Acta. 483:1-7. doi: 10.1016/j.tca.2008.09.027. 
570 Henderson T., McGregor D., and Munro, D. Editors. 2010. Detroit River Canadian Remedial

571 Action Plan: Stage 2 Report. Detroit River Canadian Cleanup, Publication No. 1, Essex, Ontario, 572 Canada.

573

574

575

576

577

578

579

580

581

582
Grøttum, J.A. and Sigholt, T. 1998. A model for oxygen consumption of Atlantic salmon (Salmo salar) based on measurements of individual fish in a tunnel respirometer. Aquacult. Engn. 17: 241-251, doi: 10.1016/S0144-8609(98)00012-0.

Heath, A. G. (1995). Water pollution and fish physiology. CRC press. USN

Handelsman, C. A., Broder, E. D., Dalton, C. M., Ruell, E. W., Myrick, C. A., Reznick, D. N., \& Ghalambor, C. K. (2013). Predator-induced phenotypic plasticity in metabolism and rate of growth: rapid adaptation to a novel environment. Integ. and Comp. Biol., 53: 975-988.

Hopkins, W.A., Rowe, C.L., and Congdon, J.D. 1999. Elevated trace element concentrations and standard metabolic rate in banded water snakes (Nerodia fasciata) exposed to coal combustion wastes. Environ.Toxicol. and Chem. 18:1258-1263. doi: 1002/etc.5620180627.

Hopkins, W.A., Snodgrass, J.W., Roe, J.H., Jackson, B.P., Gariboldi, J.C. and Congdon, J.D. 2000. Detrimental effects associated with trace element uptake in Lake Chubsuckers (Erimyzon sucetta) exposed to polluted sediments. Arch. Environ. Contam. Toxicol. 39: 193199. doi: 10.1007/s002440010096.

Hopkins, W.A., Tatara, C.P., Brant, H.A. and Jagoe, C.H. 2003. Relationships between mercury body concentrations, standard metabolic rate, and body mass in eastern mosquitofish 
589 (Gambusia holbrooki) from three experimental populations. Environ. Toxicol. Chem. 22: 586590 90. doi: 10.1002/etc.5620220317.

Jobling M. 1994. Fish Bioenergetics, Fish and Fisheries Series 13. Chapman and Hall, 592 New York.

Kashian, D. R., Drouillard, K., Haffner, D., Rause, A. , Liu, Z. and Sano, L. (2008). Final

594 Report to Michigan Sea Grant: What are the causes, consequences and correctives of fish 595 contamination in the Detroit River AOC that cause health consumption advisories? Department 596 of Biological Sciences, Wayne State University, Detroit, MI, USA, Great Lakes Institute for 597 Environmental Research (GLIER), University of Windsor, Windsor, ON, Canada, Earth, 598 Ecological and Environmental Sciences, University of Toledo, Toledo, OH, USA, Cooperative 599 Institute of Limnology and Ecosystem Research, University of Michigan, Ann Arbor, MI, USA.

600 Kauss, P.B. and Hamdy, Y.S. 1985. Biological monitoring of organochlorine 601 contaminants in the St. Clair and Detroit Rivers using introduced clams (Elliptio complanata). 602 J. Great Lakes Res. 11: 247-263. doi: 10.1016/S0380-1330(85)71768-6.

603 Killen, S.S., Marras, S., Metcalfe, N.B., McKenzie, D.J. and Domenici, P. 2013. 604 Environmental stressors alter relationships between physiology and behaviour. Trends in Ecol. 605 and Evol.,28: 651-658. doi: 10.1016/j.tree.2013.05.005.

606 Leadley, T., Balch, G., Metcalfe, C.D., Lazar, R., Mazak, E., Habowsky, J. and Haffner, 607 G.D. 1998. Chemical accumulation and toxicological stress in three Brown Bullhead (Ameiurus 608 nebulosus) populations of the Detroit River, Michigan, USA. Environ. Toxicol. and Chem.17: 609 1756-1766. doi: 10.1002/etc.5620170916. 
611 aromatic hydrocarbons in bile as a biomarker of exposure of Brown Bullheads (Ameriurus

612 nebulosus) to contaminated sediments. Environ. Toxicol. Chem. 18: 750-755. doi:

$613 \quad 10.1002 /$ etc.5620180422.

614 Lahti, K., Huuskonen, H., Laurila, A. and Piironen, J. 2002. Metabolic rate and 615 aggressiveness between Brown Trout populations. Funct. Ecol. 16: 167-174. doi $616 \quad 10.1046 /$ j.1365-2435.2002.00618.x.

617 Lunn, C.R., Toews, D.P. and Pree, D.J. 1976. Effects of three pesticides on respiration, 618 coughing, and heart rates of Rainbow trout (Salmo gairdneri Richardson). Can. J. Zool. 54: 214619 219. doi: 10.1139/z76-023. Lynch, W.E. and Norland, E.R. 2001. Winter and Summer Fish Kills in Ponds. Extension 621 Fact Sheet. The Ohio State University Extension, School of Natural Resources. Available from 622 http://ohioline.osu.edu/a-fact/0008.html [accessed August 5 2015]. MacLeod, J.C. and Pessah, E. 1973. Temperature effects on mercury accumulation, 624 toxicity, and metabolic rate in rainbow trout (Salmo gairdneri). J. Fish. Res. Board Can. 30: 485625492.

626 Merten, A. A. 2005. Sublethal narcotic impacts of dietary polyaromatic hydrocarbons on 627 the bioenergetics of and polychlorinated biphenyl (PCB) bioaccumulation in Fundulus 628 heteroclitus. Doctor of Philosophy Thesis, University of Maryland, Chesapeake Biological 629 Laboratory. 

resistance to PCB 126-induced teratogenesis in laboratory-reared offspring of killifish (Fundulus 632 heteroclitus) from a creosote-contaminated site in the Elizabeth River, VA, USA. Marine 633 Environ. Res. 54: 621-626.

Meyer, J. N. and Di Giuliuo, R. T. 2003. Heritable adaptation and fitness costs in killifish 635 (Fundulus beteroclitus) inhabiting a polluted estuary. Ecol. Applications 13: 490-503.

636 http://dx.doi.org/10.1890/1051-0761(2003)013[0490:HAAFCI]2.0.CO;2. 641 causes divergent changes in resting metabolism, depending on its relative size. Proc. Biol. Sci. 642 276: 3989-93. doi: 10.1098/rspb.2009.1219.

Norin, T. and Malte, H. 2012. Intraspecific variation in aerobic metabolic rate of fish: 644 relations with organ size and enzyme activity in brown trout. Physiol. Biochem. Zool. 85: 645645 56. doi: $10.1086 / 665982$.

647 length of exposure on metabolic rate and gill $\mathrm{Na}+\mathrm{K}+\mathrm{ATPase}$ activity of golden shiners 648 (Notemigonus crysoleucas). Comp. Biochem. and Physiol. C: Toxicol. \& Pharm..156: 24-28. 649 doi: 10.1016/j.cbpc.2012.03.003. 

salinity, and length of exposure on the metabolic rate of fathead minnows (Pimephales promelas). Comp. Biochem. and Physiol. C 148: 48-52. doi: 10.1016/j.cbpc.2008.03.004.

654 interacts with territory quality and density to determine the growth rates of juvenile Atlantic 655 salmon. Funct. Ecol. 25: 1360-1367. doi: 10.1111/j.1365-2435.2011.01894.x.

657 M.K. Denslow. N.D. and Tillitt, D.E. 2011. Gene expression changes in female zebrafish (Danio 658 rerio) brain in response to acute exposure to methylmercury Environ Toxicol Chem. 30: 301659 308. doi:10.1002/etc.409. 661 in sediments over a full life cycle. Ecotoxicol. and Environ. Safety, 54: 229-239. doi: 10.1016/S0147-6513(02)00055-6.

Selye, H. (1956). The stress of life. New York, NY: McGraw-Hill.

Sherwood, G.D., Rasmussen, J.B., Rowan, D.J, Brodeur, J, Hontela, A. (2000).

665 Bioenergetic costs of heavy metal exposure in yellow perch (Pea flavescens): in situ estimates 666 with a radiotracer $\left({ }^{137} \mathrm{Cs}\right)$ technique. Can. J. Fish. Aquat. Sci. 57:441-450. doi: and Biochem. 23: 49-53. doi:10.1023/A:1007855100185. 
Söderberg, L. 2013. Adaptive responses to aquatic pollution: Disperal physiological

671 acclimation, genetic adaptation in the Brown Bullhead (Ameiurus nebulosus). PhD Thesis.

672 Department of Biology, University of Windsor. Electronic Theses and Dissertations. Paper 4930.

Steffensen, J.F. 1989. Some errors in respirometry of aquatic breathers: how to avoid and

674 correct for them. Fish Physiol. and Biochem. 6: 49-59. doi: 10.1007/BF02995809.

675

Szalinska, E., Haffner, G.D., and Drouillard K.G. 2007. Metals in the sediments of the

676 Huron-Erie Corridor in North America: Factors regulating metal distribution and mobilization.

677 Lakes \& Reservoirs: Research \& Management 12: 217-236, doi: 10.1111/j.1440-

$678 \quad 1770.2007 .00339 . x$.

679

Szalinska, E., Grgicak-Mannion, A., Haffner, G.D., and Drouillard K.G. 2013.

680 Assessment of decadal changes in sediment contamination in a large connecting channel (Detroit

681 River, North America). Chemosphere 93: 1773-81. doi: 10.1016/j.chemosphere.2013.06.009.

682

Tatara C.P., Newman, M.C. and Mulvey, M. 2001. Effect of mercury and Gpi-2 genotype

683 on standard metabolic rate of eastern mosquitofish (Gambusia holbrooki). Environ. Toxicol.

684 Chem. 20: 782-786.

685

Upper Great Lakes Connecting Channels Study Volume I. December 1988. Executive

686 Summary. The Upper Great Lakes Connecting Channels Study Management Committee.

687 http://www.epa.gov/greatlakes/uglcc/pdfs/uglcc-198812-vol1.pdf.

Waiwood, K.G. and Beamish, F.W.H. 1978. Effects of copper, $\mathrm{pH}$ and hardness on the

12: 611-619. 
Willett, K.L., Wassenberg, D., Lienesch, L. Reichert, W. and Di Giulio, R.T. 2001. In

692 vivo and in vitro inhibition of CYP1A-dependent activity in Fundulus heterclitus by the

693 polynuclear aromatic hydrocarbon fluoranthene. Toxicol. Appl. Pharmacol. 177: 264-271.

694 Williams. R.A. Quantification of Molecular Changes in the Brown Bullhead (Ameiurus

695 nebulosus) Exposed to Environmental Toxins. 2014. PhD Thesis. Department of Biology,

696 University of Windsor. Windsor, Ontario, Canada.

697 Wirgin. I., Roy, N.K., Loftus, M., Chambers, C., Franks, D.G. and Hahn, M.E. 2011.

698 Mechanistic basis of resistance to PCBs in Atlantic Tomcod from the Hudson River. Science.

699 Vol. 331: 1322-1335. doi:10.1126/science.1197296.

700

701

702

703

704

705

706

707

708

709

710

711

712

713 
717 Table 1. Body size, standard metabolic rates $\left(\mathrm{mg} \mathrm{O}_{2} \cdot \mathrm{kg}^{-1} \cdot \mathrm{h}^{-1}\right)$ and sum PCB concentrations

$718(\mu \mathrm{g} / \mathrm{g}$ lipid) in brown bullheads from different experimental trials

\begin{tabular}{|c|c|c|c|c|c|}
\hline Trial & Population & Body Mass \pm SE (g) & $\mathrm{N}$ & $\operatorname{SMR}(95 \%)^{1}\left(\mathrm{mg} \mathrm{O}_{2} \cdot \mathrm{kg}^{-1} \cdot \mathrm{h}^{-1}\right)$ & Sum PCBs \pm SE ( $\mu / g$ Lipid $)$ \\
\hline \multirow[t]{2}{*}{ Acute } & Peche Island & $262.9 \pm 18.3$ & 23 & $80.7(69.5-87.1)$ & $0.94 \pm 0.04^{2}$ \\
\hline & Trenton Channel & $256.1 \pm 22.8$ & 21 & $97.9(91.0-105.3)$ & $7.14 \pm 0.50^{2}$ \\
\hline \multirow[t]{2}{*}{ Cleared } & Peche Island & $320.7 \pm 24.2$ & 15 & $35.6(33.3-38.1)$ & $0.61 \pm 0.09^{2}$ \\
\hline & Trenton Channel & $273.5 \pm 21.6$ & 11 & $47.6(40.8-55.5)$ & $2.65 \pm 0.162$ \\
\hline \multirow[t]{3}{*}{$\mathrm{F} 1$} & Peche Island & $46.8 \pm 8.8$ & 18 & $106.6(93.9-121.2)$ & NA \\
\hline & Trenton Channel & $35.2 \pm 5.8$ & 8 & $107.2(91.7-125.4)$ & NA \\
\hline & F1 from fish ponds & & 48 & & $0.75 \pm 0.07^{3}$ \\
\hline
\end{tabular}




\section{Figure Captions}

722 Figure 1. Raw standard metabolic rate (SMR) readings for 3 selected Brown Bullhead

723 treatments (acute, cleared and F1 groups) over time. Vertical line designates first $4 \mathrm{~h}$ period

724 which was censored from SMR calculations. Horizontal solid lines represents 4-24 h mean of

725 non-censored values, dashed horiztonal lines present $25 \%$ and $75 \%$ quartiles used to cenosor

726 outlier readings.

727

728 Figure 2. Standard metabolic rates measured in individual brown bullheads as a function of

729 body mass in each experimental trial. Top, middle and lower graphs represent acute, acclimated

730 and F1 experiments. Square symbols ( $\mathbf{\square})$ present data for Peche Island fish, open circles $(\bigcirc)$

731 refer to data for Trenton Channel fish. Solid line is the GLM predicted RMR for Peche Island

732 fish in a given experimental trial. Dashed line is the GLM predicted RMR for Trenton Channel

733 fish in a given trial.

734

735 Figure 3. Geometric mean size standardized resting metabolic rates of brown bullheads for

736 different populations and treatments. Error bars denote 95\% confidence intervals around

737 geometric mean. Hollow bars are Peche Island Fish, thatched bars are Trenton Channel fish.

738 Columns that have different letters are significantly different from one another $(\mathrm{p}<0.05$; Tukey’s

739 HSD).

740 

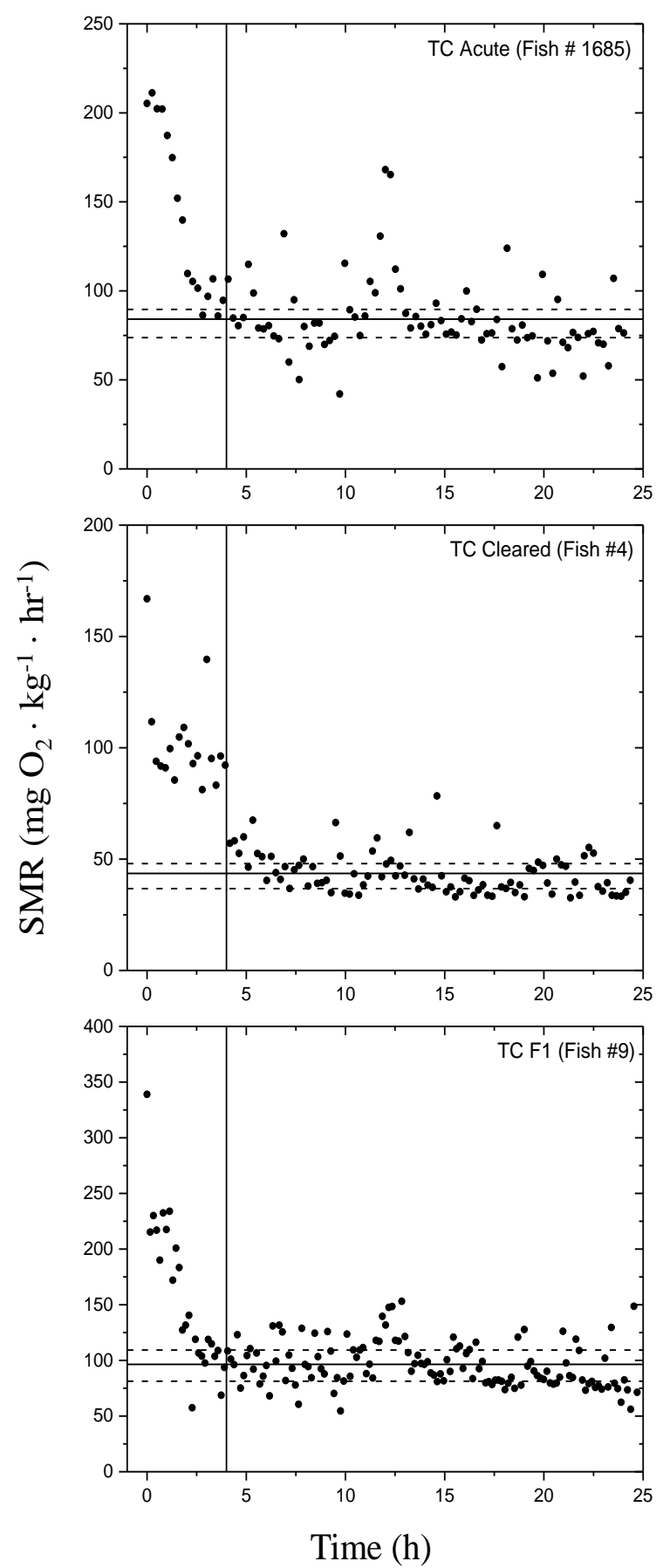

742 Figure 1 

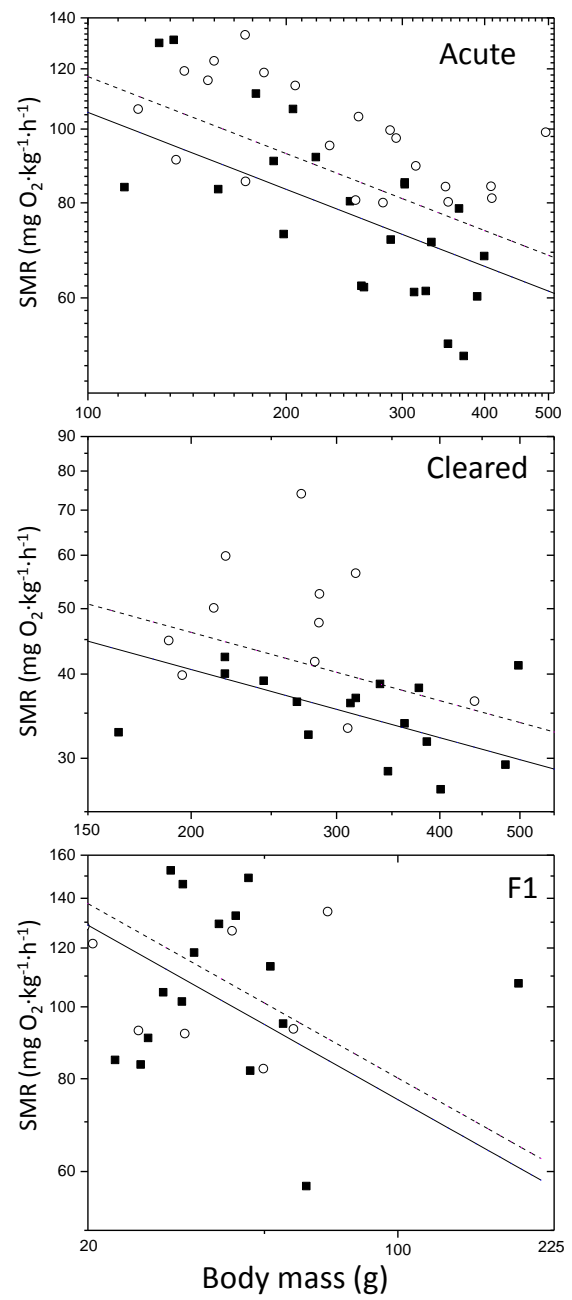

744

745 Figure 2 


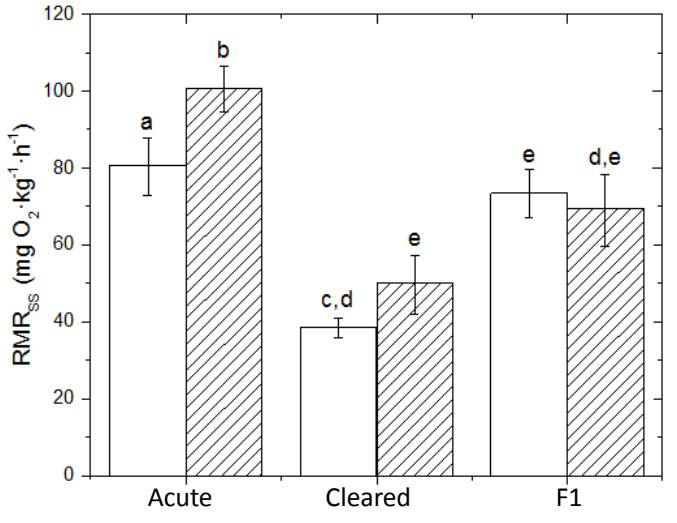

$748 \quad$ Figure 3

749 